NBER WORKING PAPER SERIES

\title{
DEBIASING THROUGH LAW
}

\author{
Christine Jolls \\ Cass R. Sunstein \\ Working Paper 11738 \\ http://www.nber.org/papers/w11738 \\ NATIONAL BUREAU OF ECONOMIC RESEARCH \\ 1050 Massachusetts Avenue \\ Cambridge, MA 02138 \\ November 2005
}

For helpful comments on this project, we are very grateful to Bruce Ackerman, Ian Ayres, Oren BarGill, Lucian Bebchuk, Cary Coglianese, Richard Craswell, Richard Fallon, Neal Feigenson, Merritt Fox, Barbara Fried, Howell Jackson, Louis Kaplow, Daryl Levinson, John Manning, Jerry Mashaw, Alison Morantz, Paul Oyer, Eric Posner, Jeffrey Rachlinski, Diane Ring, Roberta Romano, Frederick Schauer, Reva Siegel, Peter Siegelman, Matthew Stephenson, Adrian Vermeule, and participants in workshops at Boston University Law School, Columbia Law School, Fordham Law School, Harvard Law School, the John F. Kennedy School of Government at Harvard University, Stanford Law School, and Yale Law School. For outstanding research assistance, we thank John DeLong, Michael Fertik, Mindy Klenoff, Audrey Lee, Pat Robertson, Daniel Schwarcz and Mike Simkovic. The views expressed herein are those of the author(s) and do not necessarily reflect the views of the National Bureau of Economic Research.

(C2005 by Christine Jolls and Cass R. Sunstein. All rights reserved. Short sections of text, not to exceed two paragraphs, may be quoted without explicit permission provided that full credit, including $(\odot$ notice, is given to the source. 
Debiasing through Law

Christine Jolls and Cass R. Sunstein

NBER Working Paper No. 11738

November 2005

JEL No. K00, K11, K13, K22

\begin{abstract}
$\underline{\text { ABSTRACT }}$
In many settings, human beings are boundedly rational. A distinctive and insufficiently explored legal response to bounded rationality is to attempt to "debias through law," by steering people in more rational directions. In many important domains, existing legal analyses emphasize the alternative approach of insulating outcomes from the effects of boundedly rational behavior, often through blocking private choices. In fact, however, a large number of actual and imaginable legal strategies are efforts to engage in the very different approach of debiasing through law by reducing or even eliminating people's boundedly rational behavior. In important contexts, these efforts to debias through law can avoid the costs and inefficiencies associated with regulatory approaches that take bounded rationality as a given and respond by attempting to insulate outcomes from its effects. This paper offers a general account of how debiasing through law does or could work to address legal questions across a range of areas, from consumer safety law to corporate law to property law. Discussion is also devoted to the risks of government manipulation and overshooting that are sometimes raised when debiasing through law is employed.

Christine Jolls

Harvard Law School

Griswold 504

Cambridge, MA

and NBER

cjolls@nber.org

Cass R. Sunstein

University of Chicago Law School

Chicago, IL 60637

csunstei@uchicago.edu
\end{abstract}




\section{Introduction}

A growing body of legal analysis focuses on how human behavior deviates systematically from what would be predicted by the traditional economic assumption of unbounded rationality. ${ }^{1}$ To the extent that legal rules are designed on the basis of their anticipated effects on behavior, bounded rationality is obviously relevant to the formulation of legal policy. But an important and under-addressed question is precisely how it is relevant to the formulation of legal policy. The most obvious possibility is that, given a demonstration of the existence and importance of a particular aspect of bounded rationality, the law should be structured to presume the persistence of that particular feature of human behavior.

Much existing work in behavioral law and economics is of this character. Consider, for instance, the large literature suggesting that boundedly rational consumers believe potentially risky products to be substantially safer than they in fact are. If such beliefs exist, then the law might - and to some degree does - respond by adopting heightened standards of manufacturer liability for consumer products (e.g., Latin 1994). Or consider the argument that "Monday morning quarter-backing” by judges or juries adversely affects judgments reached by these decision makers on matters of corporate law, so that corporations are held liable for bad events even if preventing those events would have been extremely difficult (e.g., Rachlinski 1998). If so, then the law could respond, as indeed it has with the "business judgment rule," by largely vitiating the liability of corporate law actors, who would otherwise be vulnerable to such second-guessing on the part of adjudicators. More generally, rules and institutions might be, and frequently are, designed to curtail or even entirely block choice in the hope that legal outcomes will not fall prey to problems of bounded rationality. In the existing behavioral law and economics literature, bounded rationality "has been used to support the restriction of individual choice, almost without exception” (Rachlinski 2003, p. 1168). Boundedly rational behavior might be, and often is, taken to justify a strategy of insulation, attempting to protect legal outcomes from people's bounded rationality.

\footnotetext{
${ }^{1}$ See, for example, Jolls, Sunstein and Thaler (1998a), Korobkin and Ulen (2000), Parisi and Smith (2004), Sunstein (2000), and law review symposia in Vanderbilt Law Review (1998) and Northwestern University Law Review (2003).
} 
A quite different possibility - one that has received much less attention in the existing literature - is that legal policy may respond best to problems of bounded rationality not by insulating legal outcomes from its effects, but instead by operating directly on the boundedly rational behavior and attempting to help people either to reduce or to eliminate it. We describe legal policy in this category as "debiasing through law." Such strategies are analytically distinct in important ways from the approach of insulation and, we claim below, often represent a less intrusive, more direct, and more democratic response to the problem of bounded rationality.

In fact there exists a substantial, empirically-oriented social science literature on prospects for debiasing of individuals after a demonstration of a given form of bounded rationality. ${ }^{2}$ But empirical findings about these forms of debiasing have made only limited appearances in the legal literature, ${ }^{3}$ and equally important, social scientists interested in such forms of debiasing have generally not investigated the possibility of achieving them through law. In many important settings, empirical evidence suggests the substantial potential of these sorts of debiasing strategies, and from a legal policy perspective it is obviously important to ask about the role that law can play in facilitating such debiasing. That is our major focus in this paper.

When debiasing of individuals after a demonstration of a given form of bounded rationality has been discussed in the legal literature, the treatment has focused on existing or proposed steps taken in procedural rules governing adjudication by judges or juries. Such work complements a longstanding literature examining and responding in a range of ways to bounded rationality in the adjudicative process (see, e.g., Rachlinski 2000, pp. 753-56). A wellknown example of debiasing through procedural rules governing the adjudicative process stems from the work by Linda Babcock, George Loewenstein, Samuel Issacharoff and Colin Camerer (1995) on the tendency of litigants to evaluate likely outcomes at trial in light of their own perspectives and interests. Thus, for instance, these authors find that individuals assigned to the role of the plaintiff and presented with exactly the same information as is presented to individuals assigned to the role of the

\footnotetext{
${ }^{2}$ See, for example, Fischhoff (1982) and Weinstein and Klein (2002). Many other illustrations appear in the body of the paper.

${ }^{3}$ As noted in the text just below, where debiasing of boundedly rational actors through law has been examined in the existing literature, the focus has been on achieving debiasing through procedural rules governing adjudication by judges or juries. We discuss several examples below.
} 
defendant offer far higher estimates of the likelihood of a plaintiff victory in a lawsuit. Babcock, Loewenstein and Issacharoff (1997) find, however, that this bias may be eradicated by requiring litigants to consider the weaknesses in their case or reasons that the judge might rule against them. In these circumstances, individuals in the plaintiff's and defendant's roles have similar views on likely trial outcomes. ${ }^{4}$ The present paper, by contrast, gives primary emphasis to a different and broader form of debiasing through law a category we call "debiasing through substantive law."

The central idea of debiasing through substantive law is that in some cases it may be desirable to understand or to reform the substance of law not merely the procedures by which the law is applied in an adjudicative setting - with an eye toward debiasing those who suffer from bounded rationality. Through a series of examples from areas of law outside of the rules of adjudicative procedure, we hope to demonstrate that the project of debiasing through substantive law holds previously unrecognized promise for both understanding and improving the legal system.

Section 1 begins by offering background for our project. Section 2 focuses on debiasing through substantive law. It illustrates the general scope and power of this form of debiasing by describing the role it does or could play in addressing central questions across a range of legal domains, from consumer safety law to corporate law to property law. Our analysis of debiasing through substantive law contrasts with the more usual focus in the existing legal literature on insulating outcomes from the effects of people's bounded rationality.

Section 3 explores some of the important normative questions raised by debiasing through law (whether achieved through substantive law or through procedural rules governing the adjudicative process). Compared to the more common approach of insulating legal outcomes from the effects of bounded rationality, an important advantage of strategies for debiasing through law is that they aim to correct errors while still preserving as much opportunity as possible for people to make their own choices. Under Babcock, Loewenstein and Issacharoff's approach of debiasing through procedural rules in response to litigants' biased beliefs about trial outcomes, for instance, no decision making power or information is removed from litigants’ hands; by contrast, an “insulating” approach to litigants' bias

\footnotetext{
${ }^{4}$ It is possible that bias by real litigants - outside of an experimental setting is more resilient (Farnsworth 2003, pp. 582-85).
} 
suggests keeping information out of their hands entirely (Issacharoff and Loewenstein 1995, pp. 772-78). An important corollary of choice-preserving strategies is that they help to address boundedly rational behavior while avoiding the imposition of significant costs on those who do not exhibit bounded rationality.

At the same time, debiasing through law in either of its two varieties (substantive or procedural) raises distinctive normative concerns that require discussion. Such debiasing involves the government in a self-conscious process of changing the behavior of at least some people by altering their perceptions of the world around them. In some respects, such government action is entirely routine, as government frequently and uncontroversially regulates in response to individuals' misinformation, thereby altering perceptions in at least some instances. In extreme cases, however, debiasing through law could come to resemble a system of government propaganda in violation of widely-shared normative commitments. As our examples below will illustrate, however, many actual and conceivable forms of debiasing through law do not exhibit this problem.

\section{Bounded Rationality}

If debiasing through law is a response to bounded rationality, then an obvious first step is to understand the basic idea of bounded rationality. As is now well known in the legal literature and beyond, researchers in psychology and behavioral economics have uncovered a wide range of departures from unboundedly rational behavior. (They have also discovered other departures from traditional economic assumptions - such as the assumption that people generally exhibit narrowly self-interested rather than fairness-oriented behavior - but we focus on departures from unbounded rationality because in many cases such departures are clear mistakes that warrant correction, whereas the case of fairness-oriented behavior hardly presents a strong case for correction.)

Departures from unbounded rationality take one of two general forms. First, individuals may make judgment errors. Second, human behavior may deviate from the precepts of expected utility theory. We briefly describe these two basic categories; we hope that many readers will find them familiar, but the following description should provide a helpful background for the discussion of debiasing through law. 


\section{$1.1 \quad$ Judgment Errors}

Many judgment errors stem from "heuristics" that often shape human decision making. Begin with a familiar example of a heuristic. Asked how many words in a 2,000-word section of a novel end in "ing," people give much larger estimates than those asked how many words have " $n$ " as the second-to-last letter in the same material, notwithstanding the obvious fact that more words must satisfy the latter criterion than the former (Tversky and Kahneman 1983, p. 295). According to the "availability heuristic" at work in cases of this sort, the probability of an event is estimated after an assessment of how easily examples of the event can be called to mind. The availability heuristic often produces sensible judgments and behavior for people who lack detailed statistical information, but it also can lead to significant and severe errors. Heuristics, then, can produce important biases. Thus "availability bias” might be said to arise when the availability heuristic leads people to make predictable errors in assessing probabilities. The prospect of errors in some cases does not suggest that the behavior in question is "irrational" in the sense of being arbitrary or lacking plausible justification. The point instead is that the behavior, even if sensible in many cases, leads to systematic error in some of them. Bounded rationality is hardly the same as "irrationality" (Jolls, Sunstein and Thaler 1998b, p. 1594).

A related set of findings emphasizes not mental short-cuts, but more direct biases that lead to inaccurate judgments. An illustration is hindsight bias, in which decision makers attach excessively high probabilities to events that ended up occurring; we referred to this bias above in discussing corporate law's business judgment rule.

An important bias that has received significant attention in the legal literature on bounded rationality - and that we suggest in section 2 creates important opportunities for debiasing through substantive law - is optimism bias. Optimism bias refers to the tendency of people to believe that their own probability of facing a bad outcome is lower than it actually is. Viscusi and Magat (1987, pp. 93-95), for instance, report that roughly half of consumers they surveyed considered their own household to be below average in risk, while the other half considered their household to be average in risk - yet obviously in aggregate these perceptions cannot be correct. As summarized in Jolls (1998, p. 1659), people typically think that their chances of a range of bad outcomes, from having an auto accident to contracting a particular disease to getting fired from a job, are significantly lower than the average 
person's chances of suffering these misfortunes - although, again, this cannot be true for everyone.

While the "above average" effect just described is well established, it does not by itself establish that people optimistically underestimate their statistical risk (Viscusi and Magat 1987, pp. 95-96). For instance, people might believe that they are less likely than most people to contract cancer, while also having an accurate sense of the actual probability that they will contract cancer. But substantial evidence suggests that people sometimes exhibit optimism bias in the estimation of actual probabilities, not simply relative risk. For example, Armour and Taylor (2002, pp. 334-35) describe studies reporting that professional financial experts consistently overestimate likely corporate earnings, while business school students overestimate their likely starting salary and the number of offers that they will receive. People also underestimate their own likelihood of being involved in an automobile accident, and their frequent failure to buy insurance for floods and earthquakes is consistent with the view that people are excessively optimistic. ${ }^{5}$ It is noteworthy that these data pointing to optimism bias come from individuals making judgments that they make regularly in their everyday lives, rather than judgments far removed from those they would ordinarily make.

\subsection{Departures from Expected Utility Theory}

Along with the category of judgment errors, the idea of bounded rationality includes ways in which actual choices depart from the predictions of expected utility theory - a foundational feature of traditional economic analysis. While departures from expected utility theory have received only modest attention in the existing social science literature on debiasing of boundedly rational actors (for reasons we shall explain), below we suggest their relevance to debiasing through law.

A leading alternative to expected utility theory is Daniel Kahneman and Amos Tversky's (1979) prospect theory. According to this theory, people evaluate outcomes based on the change they represent from an initial reference point, rather than based on the nature of the outcome itself. Prospect theory also posits that people weigh losses more heavily than gains, thus showing "loss aversion."

${ }^{5}$ See Jolls (1998, pp. 1660-61) for a discussion of the relevant studies. 
Related to loss aversion is the "endowment effect," according to which an individual's valuation of an entitlement depends on whether the individual is given initial ownership of that entitlement (Kahneman, Knetsch and Thaler 1990). Thus, for example, individuals endowed with university mugs demand substantially more to sell these mugs than unendowed individuals are willing to pay to buy them - although recent evidence points to the influence of context-specific features of the environment on the occurrence of the endowment effect (Plott and Zeiler 2005).

Also related to loss aversion are framing effects. Because losses matter more than gains, framing outcomes as losses rather than gains will generally affect how people respond. ${ }^{6}$ As one example, consider the vigorous dispute over the content of a recent government advertising campaign in the United States (Peterson 2003). The advertising campaign in question involved the effects of breastfeeding of newborns. In the approach favored by breastfeeding advocates, the advertisements would refer to the risks to the child of leukemia and other diseases from not consuming breast milk - and this was the approach taken in the original version of the advertisements. Showing an intuitive understanding of prospect theory, those opposed to the original advertisements fought to have the government emphasize the advantages of breastfeeding rather than the affirmative harms (losses) of not breastfeeding. Below we discuss how the legal system might employ framing effects to engage in debiasing of boundedly rational actors.

\section{Debiasing Through Substantive Law}

This section develops a set of organizing examples of debiasing through substantive law. (The introduction and the appendix refer to existing examples of debiasing through procedural rules governing the adjudicative process.) We suggest how the idea of debiasing through substantive law can or does address important choices the legal system must make across a range of legal domains. Our discussion follows the division in section 1 above between bounded rationality in the form of judgment errors and bounded rationality in the form of departures from expected utility theory. Our goal is not to reach final conclusions about each of the legal questions we explore,

\footnotetext{
${ }^{6}$ Druckman (2001), however, shows that framing effects are less important when one of the options is endorsed by a trusted intermediary.
} 
but rather to show the potential value of debiasing through law across a number of distinct domains.

In examining debiasing through substantive law, this section focuses on forms of bounded rationality that the existing social science literature has shown to be responsive to strategies for debiasing of boundedly rational actors. This point is important because not all types of bounded rationality may respond to such strategies (see, e.g., Fischhoff 1982, pp. 427-31). We focus below on cases in which the existing social science literature has identified successful strategies for debiasing of boundedly rational actors.

As the discussion in the preceding paragraph suggests, the analysis below draws on existing empirical evidence rather than offering new evidence of ways of debiasing boundedly rational actors. There is a rich literature on prospects for debiasing of individuals after a demonstration of a given form of bounded rationality, and the next step from the perspective of legal analysis - the step we take in this paper - is to show how substantive law does or should play a role in achieving such debiasing.

\subsection{Debiasing Through Substantive Law in Response to Judgment Errors}

\subsubsection{Debiasing Through Consumer Safety Law}

A central impetus for the large body of existing law regulating consumer safety is the belief that consumers do not adequately understand the potential risks of the products they use. Consumers may not adequately understand such risks because they lack factual information, because they suffer from bounded rationality - most familiarly because of the phenomenon of optimism bias described in section 1.1 above - or both.

If the problem of limited consumer understanding (assuming there is such a problem) merely reflects a lack of information, then the traditional corrective is the straightforward provision of additional information (e.g., Stiglitz 1986, pp. 90-91). In fact in a wide range of important contexts the law requires firms to provide consumers with various types of factual information (often in specific, understandable forms), as under the Truth in Lending Act's requirement that lenders provide a range of disclosures to 
prospective borrowers. ${ }^{7}$ However, as the discussion above of optimism bias suggested and as various commentators (e.g., Latin 1994, pp. 1243-44) have emphasized, optimism bias may lead many consumers to underestimate their personal risks even if they receive accurate information about average risks a problem that may arise whenever the key piece of information to be disclosed to individuals is a probability estimate (such as the risk of harm from a product) rather than a certain outcome.

Many observers have thus concluded that optimism bias (perhaps in conjunction with other factors) justifies heightened standards of products liability as an alternative to the provision of additional statistical facts about the product in question (e.g., Prentice and Roszkowski 1991-1992). But such an approach - seeking to insulate legal outcomes from the effects of boundedly rational behavior - imposes large costs of its own, as Schwartz (1988) and others have suggested. A still more aggressive "insulating" approach, available under existing law in the case of some products, is an across-the-board ban on the product's use. A number of federal statutes give agencies a choice among disclosure requirements and partial or complete bans. ${ }^{8}$ In response to evidence of inadequate information, optimism bias, and other consumer errors, some regulators might well be tempted to impose a ban even if the statute reflects a preference for less restrictive alternatives, such as disclosure, where those alternatives are feasible. ${ }^{9}$

An alternative to these strategies for insulating legal outcomes from the effects of bounded rationality is to use the law to reduce the occurrence of boundedly rational behavior in the first instance. At the broadest level, strategies for debiasing through consumer safety law provide a sort of middle ground between inaction or the earlier prescription (in response to a simple lack of factual information) of "more information," on the one hand, and the aggressive "insulating” strategies of heightened products liability standards or outright bans, on the other. Strategies for debiasing through consumer safety law may be far more successful than the mere provision of statistical facts about average risks, and simultaneously far more protective of consumer prerogatives than the strategy of an across-the-board ban. Some strategies for debiasing through consumer protection law (including in the

${ }^{7}$ Truth in Lending Act, 15 U.S.C. §§1601-1667f.

${ }^{8}$ See, for example, Consumer Product Safety Act, 15 U.S.C. §§2051-2085;

Toxic Substances Control Act, 15 U.S.C. §§2601-2692.

${ }^{9}$ See, for example, Corrosion Proof Fittings v. EPA, 947 F.2d 1201 (5 ${ }^{\text {th }}$ Cir. 1991). 
consumer safety area) may be found in existing case law under the Federal Trade Commission Act; below we develop new and broader examples of such debiasing. ${ }^{10}$

In the discussion below of debiasing through consumer safety law, we will focus on scenarios in which optimism bias is thought to produce an overall underestimation by consumers of the risk associated with a given product. As Schwartz and Wilde (1983, pp. 1431-46), among others, have emphasized, not all settings will be characterized by significant consumer risk underestimation as a result of optimism bias. In general, optimism bias is context-dependent (Armour and Taylor 2002, pp. 338-41). Moreover, in some circumstances, a competing form of bounded rationality could lead consumers to overestimate rather than underestimate the risk associated with a product. For instance, highly available instances of accident or injury can lead to excessive pessimism - a distortion opposite the one produced by optimism bias (Schwartz and Wilde 1983, pp. 1437-38). Another possibility is that overoptimistic consumers may underestimate base-level risk but overestimate the decrease in risk from safety measures - potentially creating a positive incentive for firms to undertake such measures (Schwartz 1988, pp. 376-77). Still another possibility is that likelihoods of very low probability events will be overestimated, although the empirical evidence here is mixed, with some authors suggesting overestimation of the likelihood of very low probability events (e.g., Viscusi and Magat 1987, pp. 90-93) and other authors suggesting underestimation of the likelihood of such events (e.g., Kunreuther 1982, p. 209). Our focus in this section is on cases in which optimism bias is thought to lead to underestimation of the risks associated with a given product. ${ }^{11}$

${ }^{10}$ For discussion of existing approaches under the Federal Trade Commission Act, see Beales, Craswell and Salop (1981, pp. 495-501, 516-21); Craswell (1981); infra notes 21-22 and accompanying text.

${ }^{11}$ In addition, our focus is this specific aspect of consumer understanding rather than more general "affect-related" features of consumer understanding. For discussion of the distinction between "propositional” knowledge about products - such as the probability of harm from a product - and broader features such as “affect," see Craswell (1985, pp. 661-63). For a recent comprehensive discussion of the "affect heuristic," see Slovic et al. (2002). 


\subsubsection{Evidence on Debiasing in Response to Optimism Bias}

In the social science literature, straightforward strategies for debiasing in response to optimism bias include considering risk factors related to negative outcomes and suggesting reasons that negative outcomes might occur. In a series of studies, however, Weinstein and Klein (2002) find that such approaches fail to reduce optimism bias. ${ }^{12}$ Their findings suggest that successful debiasing strategies in response to optimism bias must take other forms. Consider two possibilities, both of which involve harnessing separate aspects of bounded rationality in response to optimism bias.

Debiasing through the availability heuristic. Building on Schwartz and Wilde's (1983, pp. 1437-38) observation about the role of availability, one response to the risk that optimistically biased individuals believe "it won't happen to them" is the availability heuristic described above. Recall our earlier example of this heuristic: individuals asked how many words in a 2,000-word section of a novel end in "ing" give much larger estimates than individuals asked how many words have " $n$ " as the second-to-last letter (Tversky and Kahneman 1983, p. 295). As described in section 1.1, use of the availability heuristic often produces a form of judgment error; as with optimism bias, availability can lead to systematic mistakes in the assessment of probabilities. (Thus "availability bias," in the form of excessively high estimates, and "unavailability bias," in the form of excessively low estimates, involve complementary errors.) But because making an occurrence “available” or readily accessible to individuals will increase their estimates of the likelihood of the occurrence, availability is a promising strategy for debiasing those who suffer from excessive optimism.

One prominent method for making an occurrence available to individuals is exposing them to a concrete instance of the occurrence. Thus, for instance, a recent series of studies of smoking behavior finds that smokers

\footnotetext{
${ }^{12}$ Weinstein and Klein note that individualized information about risk factors was found in other studies to reduce optimism bias, but we do not pursue this finding here because it is difficult to imagine incorporating such individualized information into a general legal standard. A similar point applies to the one successful debiasing mechanism reported in Weinstein (1980) in response to optimism bias; that mechanism - in which individuals were exposed to lists made by other individuals of factors improving the other individuals' chances of positive outcomes - again seems hard to translate into a recognizable legal standard.
} 
are more likely to believe that smoking will harm their health if they are aware of specific instances of such harm (Sloan, Taylor and Smith 2003, pp. 157-79). More generally, people tend to respond to concrete, narrative information even when they do not respond, or respond far less, to general statistical information (Nisbett et al. 1982, pp. 107-16). Concrete information appears to render the incident in question available in a way that can successfully counteract optimism bias.

As an illustration of the basic idea of debiasing through the availability heuristic in response to optimism bias, consider the finding of Neil Weinstein (1980, p. 810) that many people substantially underestimate their risk of cancer. Imagine that women asked to estimate their risk of breast cancer are told, before giving their estimates, a poignant and detailed story about a woman their age with similar family and other circumstances who was diagnosed with breast cancer. If so, then the empirical results described above suggest that the women's estimated probabilities will typically be higher. (Of course, they may be too much higher or not enough higher points we discuss at some length in our normative analysis in section 3 below).

Debiasing through framing. A second form of debiasing in response to optimism bias involves framing effects of the sort discussed in section 1.2 above. As we noted, people tend to weigh losses more heavily than gains in evaluating potential outcomes. This evidence suggests that framing the presentation of information to exploit the extra weight attached to losses may counteract bounded rationality in the form of optimism bias.

Consider one well-known illustration of the effects of framing. In a study involving breast cancer risk and breast self-examination, material that describes the positive effects of self-examination - such as a higher chance of discovering a tumor at an earlier stage - produces significantly less behavioral change than material that stresses the negative consequences of failing to undertake self-examination - such as a decreased chance of discovering a tumor when it remains treatable (Meyerowitz and Chaiken 1987, p. 505). Suppose that women are optimistically biased about the prospects that they will suffer from breast cancer and hence underestimate the value of engaging in recommended self-examinations. If so, then framing the recommendation to self-examine in terms of losses rather than gains should increase the probability they attach to benefiting from a self-examination, and thus should counteract optimism bias. 
Debiasing versus incentives. The examples just discussed illustrate a general point about debiasing of boundedly rational actors. Such debiasing, in our conception, does not involve providing people with improved incentives in the hope of reducing their bounded rationality. In some cases providing incentives may in fact diminish people's bounded rationality. For instance, many people are markedly prone to social influence and will ignore even the clear evidence of their own senses, and hence provide incorrect answers, if they are confronted with the unanimous views of others (Asch 1955); but this tendency turns out to be significantly reduced when people stand to gain financially from giving correct answers, as long as task difficulty is not too high (Baron, Vandello and Brunsman 1996).

A broad definition of debiasing of boundedly rational actors might embrace the use of incentives to reduce bounded rationality (Fischhoff 1982, p. 424). A more conservative view, however, is that if an apparent departure from unbounded rationality is eliminated with the provision of financial incentives, then the apparent departure was not a departure from unbounded rationality at all, but instead a mere result of lazy or careless decision making by an actor who had no reason to be other than lazy or careless.

In the analysis above and below, we emphasize this more conservative definition and focus on cases in which behavior changes not from the provision of financial incentives, but rather from intervening in and altering the situation that produces the boundedly rational behavior. Under this conception of debiasing of boundedly rational actors, individuals are not asked to repeat the very same task with the very same structure, with the sole difference that they now have greater reason to take care in making their choices; instead the environment is restructured in a way that alters not individuals' motivation but the actual process by which they perceive the world around them.

\subsubsection{Legal Implications}

We now apply the two forms of debiasing in response to optimism bias developed above to the context of consumer safety law.

Debiasing through the availability heuristic. In the consumer safety context, debiasing through the availability heuristic would focus on putting at consumers' cognitive disposal the prospect of negative outcomes from use, or at least unsafe use, of a particular product. Specifically, the law could require 
firms - on pain of administrative penalties or tort liability - to provide a truthful account of consequences that resulted from a particular harmproducing use of the product, rather than simply providing a generalized warning or statement that fails to harness availability. (Recall the example from above of an account of a specific woman's experience suffering from breast cancer.)

Familiar in existing consumer safety law are generalized warnings, such as the statement on every package of cigarettes sold in the United States that smoking may be hazardous to one's health; but the evidence suggests that the approach of requiring the specific account as opposed to the generalized statement would help to reduce optimism bias (Nisbett et al. 1982). Ideally the specific account of harm described here would change occasionally to avoid the phenomenon of "wear-out," in which consumers learn to tune out messages that are repeated too often (e.g., Craig, Sternthal and Leavitt 1976). ${ }^{13}$

Our general point here is similar in spirit (although we do not suggest a specific requirement of vividness, as emphasized below) to Chris Guthrie's suggestion that legal policy makers should bring "vivid information about plaintiff losses in frivolous litigation" to bear in reducing plaintiffs' overestimation of the probability of success in such litigation - an illustration of debiasing through procedural rules governing the adjudicative process (Guthrie 2000, p. 210). The emphasis on specific narratives also avoids the difficulty of coming up with an accurate numerical probability estimate (Schwartz and Wilde 1983, pp. 1459-60). Analogies to the approach proposed here for the consumer safety context could be imagined as well for the important domain of securities disclosure - a domain in which the Securities and Exchange Commission has for long struggled with the issue of effective communication of risks to prospective investors. ${ }^{14}$

${ }^{13}$ It is possible that, as Douglas Kysar (2003, pp. 1785-1786 and n364) has noted, consumer safety strategies for insulating legal outcomes from the effects of bounded rationality - as opposed to the strategies discussed here for debiasing through law - would give some firms indirect incentives to provide the sorts of truthful accounts (emphasizing "people or anecdotes" rather than "statistics," to use Kysar's phrasing) that we advocate here. Our emphasis, however, is on these more direct strategies for debiasing through substantive law.

${ }^{14}$ See, for example, Securities and Exchange Commission, “Concept Release on Improving Descriptions of Risk by Mutual Funds and Other Investment 
Of course, for information - of whatever sort - to matter to decision makers, it must come to their attention. Thus, in the consumer safety context the law might require that the real-life story of accident or injury be printed in large type and displayed prominently, so that consumers would be reasonably likely to see and read it before using the product. Still, for some of the reasons developed most prominently by Howard Latin (1994) - for instance, the simple fact of illiteracy among a nontrivial fraction of consumers - no warning or statement will be guaranteed to reach each and every product user. A further important note concerns the prospects for manufacturers' influence over consumer perceptions; as Edward Glaeser (2004, p. 410) writes, "One should expect to see a proliferation of misleading signals and other cues when incorrect beliefs are complements to buying sellers' commodities." In our context, this influence suggests the importance of maintaining some legal control over the nature and format of the accounts manufacturers are required to provide. It is possible that manufacturers, influenced by market pressures, would manage to subvert attempts to achieve debiasing through the availability heuristic. At the same time, with such debiasing as with any informationally-oriented strategy, there are important countervailing benefits to limiting the degree of "overspecification" of messages (Beales, Craswell and Salop 1981, pp. 535-36), and the ultimate question of the optimal form of debiasing through the availability heuristic is an empirical one. ${ }^{15}$

Debiasing through the availability heuristic-limits. The effort to achieve debiasing through the availability heuristic in consumer safety law should be modest along two separate dimensions. First, a successful strategy

Companies,” 60 Fed. Reg. 17,172 (Apr. 4, 1995); see also Securities and Exchange Commission Form S-1, Pt. I, Item 3 (requiring disclosure of information required by Item 503 of Regulation S-K); Securities and Exchange Commission Regulation S-K, §503(c) (requiring disclosure of risk factors).

${ }^{15}$ A further important benefit of using availability to counteract optimism bias in the consumer safety context is that such an approach would improve not only the decision making of consumers suffering from optimism bias but also that of consumers suffering from a simple lack of information. A conspicuous, prominent account of injury from a product should help to correct the estimated probability of harm attached to the product by an optimistically biased consumer but is also likely to improve the behavior of consumers suffering from a simple lack of information. 
would need to target a limited number of discrete products for which the problem of consumer optimism bias was most clear and important. (As noted above, in some contexts there may not be a problem of consumer optimism bias at all.) Consumers would begin to suffer from "information overload" if every time they went to buy any product - from a lawnmower to a candy bar to a fast food hamburger - they were hit with a real-life story of an individual harmed by use or consumption of the product. Their natural response might be to tune out all of the accounts provided by firms, even assuming these accounts were prominently displayed (e.g., Magat and Viscusi 1992, pp. 18586). ${ }^{16}$

Second, the law would need to avoid overreaching with respect to the severity of the featured outcomes; this is especially important in light of the fact, noted above, that optimism bias is adaptive in many contexts, and, thus, there is certainly little to be gained from transforming consumers into thoroughgoing pessimists. Firms should not be required to provide anecdotes reflecting highly unusual consequences of using their products, as an emphasis on worst-case scenarios could produce excessive responses (Sunstein 2002). If requirements of anecdote-based warnings sweep in extremely unusual or unlikely scenarios, consumers might overreact - or alternatively they might lose faith and fail to attach any weight at all to the accounts. Of course there are line-drawing problems here, but the basic point is straightforward.

Note in addition that worst-case scenarios are likely to be much more easily avoided with our suggestion of a legal requirement that firms provide truthful anecdotes about genuine harms than with the alternative strategy frequently used by government - of public information campaigns concerning risky consumer products. Such campaigns have often resulted in the use of extremely vivid and salient images, to the point of seriously risking overreaction or even backlash as a result of citizens' perceptions of government “manipulation.” In the smoking context, for instance, the European Union has experimented with requirements that a percentage of cigarette packages sold have their fronts covered with vivid pictures of

${ }^{16}$ Elsewhere Viscusi (1988, pp.298-301) discusses ways of implementing multi-tiered warning systems, where high-risk products contain warnings on their labels while stores offer reference books with risk information for lowrisk products. 
rotting lungs. ${ }^{17}$ We think the approach suggested here is sounder because it is more restrained. Like the European Union, the Canadian Health Ministry has required not only clear warnings ("Cigarettes cause strokes," "Tobacco smoke hurts babies," and "Tobacco use can make you impotent”) but also graphic pictures such as highly disfigured gums and lungs with cancerous tumors. ${ }^{18}$ Likewise, in the United States a well-known anti-drug advertisement from the 1980s featured a picture of an egg frying in a pan with the voiceover, "This is your brain on drugs" (Dewan 2004). Again, we think it is often valuable to avoid such extreme messages.

Overall, our suggestion of requiring, on pain of administrative sanctions or tort liability, truthful narratives of harm is a more modest and measured response to optimism bias than the approaches just described approaches that harness availability by aggressively exploiting highly salient, gripping images and that for this very reason may run an especially high risk of manipulation, overshooting, and other problems.

Debiasing through the availability heuristic-analogies to existing practice. The idea of requiring firms to provide truthful accounts of harm has analogies in current practice. The American Legacy Foundation, an organization founded out of the 1998 settlement agreement between the United States tobacco industry and state attorneys general, ${ }^{19}$ has launched an information campaign employing a close parallel to the strategy outlined here of debiasing through the availability heuristic. The Foundation has publicized, in leading national magazines and on the internet, parting letters to children and other loved ones from mothers dying of smoking-related diseases. For instance, one letter reads, "Dearest Jon, I am so sorry my smoking will cheat us out of 20 or 30 more years together. Remember the fun we had every year at the lake. I will ALWAYS love and treasure you. Linda." ${ }^{20}$ Our suggested approach reflects much the same spirit - although, as

${ }^{17}$ See http://lists.essential.org/pipermail/intl-tobacco/2001q1/000426.html (visited 6/16/2005).

${ }^{18}$ See

http://www.hc-sc.gc.ca/hecs-sesc/tobacco/legislation/warnings/warnings.html (visited 7/5/2005).

${ }^{19}$ See http://www.adcouncil.org/orgs/american_legacy_foundation/ (visited 8/18/2005).

${ }^{20}$ See http://women.americanlegacy.org/includes/pdfs/ad2.pdf (visited 8/19/2005). 
already indicated, firms required to provide truthful accounts would almost certainly choose ones less vivid and heart rending than this one.

Our suggested approach also has a kindred spirit in the existing law of deceptive advertising under the Federal Trade Commission Act. ${ }^{21}$ This Act generally prohibits firms from conveying information to consumers in ways that risk consumer misperception. ${ }^{22}$ Under this law, the Federal Trade Commission has restricted advertisements that profile one or two specific accounts of success or benefit, based on the concern that consumers will overestimate the probability of having a similar experience (Craswell 1985, pp. 704-05). In a very real sense, the law of deceptive advertising is thus a form of debiasing through substantive law; like our proposed approach here, it adopts a middle ground between inaction or naive informational strategies, on the one hand, and the "insulating" strategies of heightened liability standards or outright bans, on the other. Of course, the law of deceptive advertising concerns limits on affirmative statements (advertisements) firms choose to undertake, while the proposal here concerns requirements that firms affirmatively provide information in particular ways; but in both cases the underlying attempt is to use law to reduce the severity of consumer error.

Debiasing through framing. Framing effects also point toward potentially effective methods of debiasing through substantive law in the consumer safety context. Suppose that firms are affirmatively opting to provide information or are providing information in response to a legal requirement that does not specifically set forth the form of the information. If so, firms' interest will often be in framing the information in a way that minimizes the risks perceived by consumers. (Recall the shrewd actors described in section 1.2, who showed an intuitive appreciation of loss aversion in objecting to advertisements emphasizing the losses from not breastfeeding rather than the gains from breastfeeding.) A strategy of debiasing through substantive law in response to consumers' optimism bias is to require that firms identify the potential negative consequences associated with their product or a particular use of their product, rather than the positive consequences associated with (for instance) an alternative usage.

Such a requirement would, like the law of deceptive advertising discussed above, concern statements that firms affirmatively choose to make;

21 U.S.C. $\S \S 41-58$.

${ }^{22}$ See Beales, Craswell and Salop (1981, pp. 495-501) for a useful summary and discussion. 
it could also be applied to statements they are legally required to make under independent legal provisions. The strategy noted here for debiasing through substantive law could make significant progress toward ensuring that consumers have a more accurate understanding of the risks associated with particular products. It could also reduce the need for either a complete ban on some of the products in question or other approaches that insulate legal outcomes from the effects of bounded rationality by curtailing consumer choice.

\subsubsection{Debiasing Through Corporate Law}

A basic question in corporate law concerns the optimal breakdown in the composition of corporate boards of directors between so-called "inside" and "outside" directors. Inside directors are those who are primarily employed by or otherwise closely connected with the corporation; outside directors, by contrast, have no such close links to the firm.

Several arguments support the inclusion of at least some outside directors on the board (e.g., Brudney 1982, pp. 598-99 and n3). Of particular relevance for our purposes is the idea that such directors may help to overcome various biased judgments on the part of inside directors (Langevoort 2001, p. 803). For instance, inside directors may fall prey to optimism bias in predicting corporate outcomes (e.g., Langevoort 2001, p. 809). To be sure, there are settings in which inside directors may not exhibit boundedly rational behavior on balance - for instance because optimism bias is counteracted by an excessive level of managerial reluctance to take risks just as we suggested in section 2.1.1 above that in some settings consumers might not, on balance, underestimate product risks.

In settings in which inside directors do exhibit optimistically biased decision making, one possible response is to insulate outcomes from the effects of the optimism bias by removing certain board decisions from the inside directors' hands. By contrast, an approach of debiasing through substantive law would, following Langevoort's argument above, ${ }^{23}$ take the form of increasing the number of outside directors on the board. Existing law

${ }^{23}$ Langevoort himself, however, does not ultimately join those pressing for increases in outside directors on corporate boards. 
has gone in just this direction in the time since Langevoort wrote. ${ }^{24}$ Might this new approach constitute an effective form of debiasing through substantive law?

\subsubsection{Evidence on Debiasing in Response to Optimism Bias (Again)}

For outside directors on corporate boards to serve as agents for debiasing of optimistically biased inside directors, two things would have to be true. First, outside directors would have to be less subject to optimism bias than inside directors. Second, the involvement of outside directors would have to alter the judgments of inside directors - perhaps even through the use, by outside directors, of some of the forms of debiasing discussed in section 2.1.1 above. What do we know about each of these two empirical propositions?

The degree of optimism bias exhibited by inside versus outside directors has not been rigorously explored, but the corporate law literature suggests two reasons for believing that outside directors will show a lesser degree of such bias than inside directors (Langevoort 1998, pp. 139-41; Langevoort 2001, pp. 803, 809). The first is that, relative to inside directors, outside directors' self-conception and esteem are less closely bundled up with the firm's fortunes. The second reason is that, relative to the selection of inside directors, the selection of outside directors is less likely to be heavily influenced by whether candidates have highly optimistic views of the firm's prospects.

But will some minimum number of outside directors improve the judgments reached by inside directors? A large body of empirical evidence shows that erroneous judgments often result when deliberations are undertaken by like-minded people; those who agree with one another typically end up at a more extreme point in line with their predeliberation tendencies. ${ }^{25}$ In the context of corporate boards, the prediction is that optimistic members will lead one another in the direction of further optimism and excessive risk-taking - what has been termed the "risky shift" (Brown 1985, p. 204). As a result, boards might well end up more optimistic than the

${ }^{24}$ See Sarbanes-Oxley Act of 2002, Pub. L. No. 107-204, § 301; infra note 26 and accompanying text.

${ }^{25}$ See Sunstein (2003, pp. 111-18, 128-35) for a discussion of this body of evidence. 
median board member before deliberation began. Therefore, the mandated inclusion of outside directors might well serve to check deliberative processes that fuel unrealistically optimistic decisions. But the strength of the case for an effect of outside directors on inside directors' - or corporate boards' ultimate - judgments should not be overstated, as corporate law scholars have often noted evidence of the general limits on outside directors' effectiveness (e.g., Romano 1996, pp. 286-90; Bhagat and Black 1999, pp. 923-50).

\subsubsection{Legal Implications}

A requirement of the recently-enacted Sarbanes-Oxley Act is that a threshold number of outside directors must be named to the corporate boards of covered firms. Specifically, the Act requires that such firms use outside directors to perform all auditing functions ${ }^{26}$; this requirement guarantees a minimum number of outside directors on the board. The requirement of independent directors - reflected as well in various exchange-listing rules (e.g., Bhagat and Black 1999, p. 933) - can be understood, in its legal incarnation in the Sarbanes-Oxley Act, as a form of debiasing through substantive law. The reason is that the presence of the outside directors responds to the risk of optimism bias on the part of boards stacked with inside directors. Note that our suggestion is not that the Sarbanes-Oxley Act's requirement of outside directors was actually motivated by a desire to engage in such debiasing; the corporate governance provisions of the Act, including the outside director requirement, appear to have been the product of entirely different forces (Romano 2005, pp. 1543-94).

Corporate law rules governing the structure of the board of directors may be a reasonable way to reduce the degree of optimism bias exhibited by inside directors. Of course, it is possible that market pressures will impose meaningful constraints on optimism bias on the part of inside directors. ${ }^{27}$ But at the same time, other forces may increase the degree of optimism bias such actors exhibit; these include the link between inside directors' optimistic judgments and their self-esteem and the process by which such directors are selected (Langevoort 1998, pp. 139-41; Langevoort 2001, p. 809). Of course,

${ }^{26}$ Sarbanes-Oxley Act of 2002, Pub. L. No. 107-204, § 301.

${ }^{27}$ Tor (2002) provides analysis of the effects and limits of market pressures as a constraining force on various biases in the context of firm entry into new industry. 
wholly apart from the requirements of Sarbanes-Oxley, many boards do contain some or even a majority of outside directors, and this may represent a self-conscious effort by firms interested in (among other things) combating the problem of optimism bias on the part of inside directors; indeed, some firms might wish to go even further and appoint a "chief naysayer" to combat such optimism bias (Paredes 2004). A legal requirement such as SarbanesOxley, however, is likely to facilitate such debiasing for a broader range of firms, although at a cost of requiring outside directors on all covered boards notwithstanding the likelihood of firm- and industry-specific variation in ideal board structure. We return to this last point in section 3.4 below.

2.2 Debiasing Through Substantive Law in Response to Departures from Expected Utility Theory

Social scientists have paid little attention to debiasing in response to departures from expected utility theory (in contrast to debiasing in response to judgment errors). The reason may be that such departures are not unambiguous "errors," and thus it is controversial to say (for example) that the endowment effect, or loss aversion, is a kind of mistake that requires correction. Perhaps for the same reason, strategies for insulating outcomes from the effects of bounded rationality - familiar in the contexts discussed in section 2.1 above - are less prominent where departures from expected utility theory are in play.

Our emphasis in this section is on the endowment effect, which (as discussed in section 1.2 above) says that individuals' willingness to accept the amount at which they would sell an entitlement - differs from their willingness to pay - the amount they would pay to purchase the same entitlement. As suggested by our comment just above, the endowment effect generally cannot be said to be an "error" in the sense of the judgment errors discussed in section 1.1, where individuals are making objective mistakes in estimating probabilities; instead the endowment effect may be a reflection of potentially valid reasons for the difference between willingness to accept and willingness to pay. In some contexts, however, a decision maker may determine that either willingness to accept or willingness to pay is the "correct" measure of value. Such settings are our focus in this section; we consider the role of debiasing through substantive law in moving toward the chosen measure of value, which itself is taken as a given rather than independently justified in our analysis. We refer briefly to the question of a chosen measure of value in section 3.3 below. 


\subsubsection{Debiasing Through Property Law}

With the ever-growing importance of intellectual property, the legal protection awarded to creators of such property is a central question of property law. For any property law entitlement, an important aspect of its legal protection is whether the entitlement is protected by a "property rule" or a "liability rule" (Calabresi and Melamed 1972). Under a property rule, entitlement holders are not required to part with their entitlements unless they voluntarily agree (typically in a bargained-for exchange) to do so. Under a liability rule, by contrast, entitlement holders may be forced to give up their entitlements as long as they are paid a legally-specified amount in damages.

The American and European intellectual property systems differ significantly in their reliance on property rules versus liability rules. Where, for instance, an entitlement holder wishes to make use of related intellectual property owned by another entity, in the United States the entitlement holder generally faces a property rule regime, whereas in many European countries the entitlement holder faces a liability rule regime (Merges 1996, p. 1316). In the analysis just below, we assume that a decision maker has determined that lowering willingness to accept to the level of willingness to pay for an intellectual property entitlement (in cases in which these two measures differ) is desirable, and we then explore how the choice between property and liability rules might play a role in achieving this effect. Our basic conclusion is that the European systems, in the domains in which they adopt liability rule protection, may achieve a form of debiasing through substantive law given the assumed desirability of lowering willingness to accept to the level of willingness to pay.

\subsubsection{Evidence on Lowering Willingness to Accept to the Level of Willingness to Pay Through the Use of Liability Rules}

A preliminary empirical study by Jeffrey Rachlinski and Forest Jourden (1998) points to a potential relationship between the divergence between willingness to accept and willingness to pay and the way in which the entitlement being valued is protected from violation. Rachlinski and Jourden's study finds a marked reduction in the disparity between willingness to accept and willingness to pay when liability rules rather than property rules protect the entitlement in question. In the standard endowment effect pattern, 
willingness to accept is well above willingness to pay when the entitlement is protected by a property rule. But Rachlinski and Jourden find that when it is protected by a liability rule, willingness to accept falls to the level of willingness to pay, consistent with the hypothesis offered in earlier work by Ian Ayres and Eric Talley (1995, pp. 1101-02).

Rachlinski and Jourden explain their results by suggesting that "[a] right that is protected by a damages remedy might convey less of a sense of ownership than does a right that is protected by an injunctive remedy" (Rachlinski and Jourden 1998, p. 1560). Such incomplete ownership may prevent a perfection of the emotional attachment that is harbinger of the endowment effect. Subjective value, in short, may well be lower when a right is protected by a liability rule. Rachlinski and Jourden's empirical findings suggest that in domains in which lowering willingness to accept to the level of willingness to pay is desirable, liability rules may be preferable to property rules - although of course a complete analysis of the choice between property and liability rules involves many additional considerations (Kaplow and Shavell 1996).

\subsubsection{Legal Implications}

Under Rachlinski and Jourden's findings, the European system of intellectual property protection, in the domains in which it adopts a liabilityrule approach, achieves a form of debiasing through substantive law (again given our background assumption that bringing willingness to accept down to the level of willingness to pay in the context in question is desirable). The European approach in these domains eliminates the endowment effect by moving individuals' willingness to accept into line with their willingness to pay.

It remains to be seen whether the device of choosing liability rules over property rules in protecting intellectual property entitlements would generally have the effect of reducing willingness to accept to the level of willingness to pay for these entitlements. Holders of intellectual property entitlements might be unaware of how, exactly, their entitlements are protected; if intellectual property law uses liability rules rather than property rules, perhaps many entitlement holders will not be aware of it. Note also that in Rachlinski and Jourden's study, the entitlements at issue involved environmental amenities, not intellectual property. In the distinctive context of environmental amenities, the occurrence of the endowment effect under a 
property rule may have been "motivated by subjects' belief that it is improper to sell an environmental resource that one can protect," while this belief was not triggered under a liability rule "because the law permitted the destruction of the resource for a price” (Korobkin 2003, p. 1285). Absent the societal commitment to environmental amenities, for which people often demand a great deal and may even refuse to sell at any price at all, it remains possible that the choice between property and liability rules would not have the same impact on willingness to accept versus willingness to pay. Further empirical work could help to shed light on this question. ${ }^{28}$

It should also be emphasized that one can question whether the willingness to pay measure is in fact the correct value in the context of intellectual property entitlements; as noted above, we have not sought to provide an independent defense of that position here. On one view, there is no correct value; when a person owns some entitlement $X$, the person simply values it more than when the person must purchase it. Whether it is right to say there is no correct value depends on the reason for the endowment effect. Suppose, as is sometimes hypothesized, that the high value placed on things that one owns is a product of a failure to appreciate opportunity costs - an undervaluation of the costs of refusing to sell such items. If so, the willingness to pay measure is to be preferred because it does not reflect this distortion in judgment.

\subsubsection{Debiasing Through Agency Law}

In the context of merchants, a strong endowment effect will make merchants reluctant to sell their goods. If the excess of willingness to accept over willingness to pay in this context is undesirable, then might debiasing through substantive law be possible in this domain? We describe below how the law of agency may constitute a form of such debiasing.

\footnotetext{
${ }^{28}$ Lewinsohn-Zamir (2001, pp.253-55) argues, but without presenting any direct empirical evidence, that property rules may be preferable to liability rules for reducing the endowment effect in some contexts.
} 


\subsubsection{Evidence on Lowering Willingness to Accept to the Level of Willingness to Pay Through the Use of the Agency Relationship}

An empirical paper by Jennifer Arlen, Matthew Spitzer, and Eric Talley (2002) demonstrates the prospects for debiasing of boundedly rational actors exhibiting the endowment effect (again assuming it is desirable to eliminate the excess of willingness to accept over willingness to pay). Arlen, Spitzer and Talley find that actors exhibit the standard excess of willingness to accept over willingness to pay when they are acting in their ordinary individual capacities - but not when they are acting in the role of corporate managers in a business agency context. Individuals who are instructed that they are acting as agents for the corporation that employs them "manifest[] virtually no endowment effect whatsoever” (Arlen, Spitzer and Talley 2002, p. 5).

What explains these findings? Two likely explanations involve the business context and the manager's agency relationship with the firm. ${ }^{29}$ Someone working in business - even if acting not as the agent of a corporation but as a sole proprietor - will probably exhibit less of an endowment effect than someone acting in an ordinary individual capacity. One might think, for instance, that transactions conducted by a shoe store whether or not the store is run by a manager - would not exhibit a large endowment effect. Such a store would be unlikely to stay in business long if a strong endowment effect led it - whether acting through a manager or a proprietor - to price shoes at an amount well above people's willingness to pay.

It seems likely, however, that the agency relationship further dampens the tendency toward exhibiting an excess of willingness to accept over willingness to pay. This is so because the endowment effect is often linked to a desire by entitlement holders to avoid regretting a bad decision to engage in a transaction (sale of the entitlement). ${ }^{30}$ By contrast, agents will tend to be less likely than ordinary individuals to experience regret because their personal stake in the outcomes that occur is lower (Korobkin 2003, p. 1255).

${ }^{29}$ Korobkin (2003, p. 1279) emphasizes that a third explanation may be the certainty of the entitlement value in Arlen, Spitzer and Talley's agency relationship.

${ }^{30}$ For recent discussions, see Camerer, Issacharoff, Loewenstein, O’Donoghue and Rabin (2003, pp.1224-25); Korobkin (2003, pp.1254-55). 
Thus, it is reasonable to conjecture that the agency relationship itself helps to account for the finding of an absence of an excess of willingness to accept over willingness to pay in a business agency relationship - although of course a definitive empirical study separately testing the two explanations could help put the conclusion on firmer ground.

\subsubsection{Legal Implications}

An implication of Arlen, Spitzer and Talley's empirical findings is that existing rules of agency law, in structuring the relationship between corporations and their managers, may achieve a form of debiasing through substantive law for managerial actors (assuming, again, that it is desirable to eliminate the excess of willingness to accept over willingness to pay). Acting in the context of the relationship specified by the default rules of agency law, individuals may not display the endowment effect that has proven robust in other settings. Note that our focus here, as in our discussion above of the Sarbanes-Oxley Act, is on the (perhaps unanticipated) effects of the law rather than the particular motives of legislators or other actors in enacting it.

In theory, the obligations associated with a business agency relationship could be specified by privately negotiated arrangements rather than by the default rules of agency law. Such arrangements could ensure that much of business is done by agents acting on behalf of firms under a specified set of duties. Indeed, this may be what Arlen, Spitzer and Talley (2002, p. 33) have in mind when they suggest that "the nexus of relationships often identified with 'the firm' may operate (at least in part) as a debiasing mechanism, thereby representing an underappreciated consequence of organizing trade within firms." However, as Frank Easterbrook and Daniel Fischel (1982, p. 702) have suggested, arrangements negotiated within firms may impose extremely high costs, particularly given "the difficulty that contracting parties have in anticipating when and how their interests may diverge"; therefore our point here, following Easterbrook and Fischel, is to emphasize the valuable role of law in achieving the debiasing described above. According to Easterbrook and Fischel, the complexity and nuance of the requirements to be imposed within the firm point to the important value of legal rules. Our argument is simply that the basic rules of agency law provide an illustration of how existing rules may sometimes accomplish debiasing through substantive law. 


\section{Normative Issues in Debiasing Through Law}

In many settings, debiasing through law, whether achieved through substantive law or through procedural rules governing the adjudicative process, provides a more direct and effective response to problems of bounded rationality than the more typical approach of insulating legal outcomes from the effects of boundedly rational behavior that itself is taken as a given. Below we develop and defend this central claim about the normative appeal of debiasing through law in its substantive and procedural law incarnations. We also address possible normative objections to debiasing through law; some of these apply to "insulating" strategies as well, while others are distinctive to debiasing through law. Because much of our analysis below will address comparisons with "insulating” strategies, it is important to emphasize that our conception of debiasing through law does not embrace notions of legally-related "debiasing" that encompass various forms of insulation (e.g., Gulati, Rachlinski and Langevoort 2004). ${ }^{31}$

${ }^{31}$ Gulati, Rachlinski and Langevoort (2004) use the term “debiasing” to refer in a broad way to the potential response of the "fraud by hindsight" rule of securities law to the problem of hindsight bias. Some of the effects they include in their "debiasing" category - for instance, "insulat[ing] judgments from the hindsight bias" (p. 781) and requiring courts to use "ex ante standards, such as generally accepted accounting principles” (p. 792) - fall into the "insulating" category rather than the "debiasing through law" category within our framework. Likewise, Langevoort (1998, p. 1510) refers to proposals for addressing hindsight bias in Jolls, Sunstein and Thaler (1998a) as "mechanisms for debiasing," but within our framework these proposals are "insulating" strategies because they take hindsight bias as a given and then seek to reduce or eliminate its effects on legal outcomes. Our use of the term "debiasing" to refer specifically to situations in which bounded rationality diminishes, as opposed simply to having its effects on outcomes blunted by a legal rule, seems more consistent with the accepted meaning of "debiasing" in the social science literature, as in that literature debiasing refers to reducing people’s manifestation of boundedly rational behavior in the first instance. 


\subsection{Normative Analysis - In General}

In the areas discussed thus far, and in many imaginable contexts, social planners might choose among three categories of approaches to decisions stemming from bounded rationality: "insulating” strategies, strategies for debiasing through law, and refusing to respond at all. And of course a range of options might present themselves within the first two categories. In our view the appropriate choice depends on the consequences and hence on close engagement with particulars.

It is easy to imagine situations in which bounded rationality presents a modest problem, so that any cure is worse than the disease. If some boundedly rational consumers are purchasing excessively safe cars, because the availability heuristic has led them to overestimate risks, the argument for a governmental response does not seem particularly strong, at least if it assumed that the social costs of the relevant purchases are low. A governmental response is also likely to be unwarranted where people are able to correct their own errors (e.g., Rachlinski 2003, pp. 1206-19; Rasmussen 1998, pp. 1697-98). And in some circumstances, “insulating” strategies will be the best alternative. Suppose, for example, that a particular bias leads most people to unambiguous and extremely serious error, and also that efforts at debiasing through law are likely to fail. If so, it might well be best simply to foreclose certain choices. But in other circumstances, the argument for debiasing through law will be convincing - as, for example, when a refusal to respond to bounded rationality will ensure large welfare losses, and when debiasing through law will be less costly than any alternative.

We suspect that some of the examples given in section 2 fall in this category, for several reasons. First, as emphasized especially in the discussion of consumer safety law in section 2.1.1 above, a special virtue of debiasing through law is that, relative to many "insulating" strategies, it maximizes the preservation of people's opportunity to make choices. Instead of blocking decisions, it is preferable to attempt to improve decision making (Rachlinski 2003, p. 1224). It is a familiar point that choice-preserving remedies of this general nature are valuable because they acknowledge both that individuals have diverse preferences and that planners may err (e.g., Beales, Craswell and Salop 1981, pp. 513-14; Viscusi and Magat 1987, pp. $60-61$ ). If some sort of governmental response to consumer optimism bias is warranted, then debiasing through law may be the best strategy. 
A second virtue of debiasing through law is that it reduces the effects of legal intervention on those not suffering from bounded rationality in the first place. In responding to problems of bounded rationality, it is preferable, when possible, to develop legal approaches that avoid imposing significant costs on those who do not exhibit boundedly rational behavior (Camerer et al. 2003, p. 1212). As observed by Gregory Mitchell (2002, pp. 132-35), strategies for debiasing of boundedly rational actors will often make it possible for government to improve outcomes for individuals who exhibit bounded rationality while leaving largely or entirely unrestricted the choices of those who would not otherwise err - a point we elaborate as well as qualify below..

It bears emphasis, however, that our goal in this paper is not to offer final recommendations about, or systematic comparisons for, any particular problem, including those discussed in section 2. Instead our goal is to illustrate the potential uses and generality of the approach of debiasing through law, especially debiasing through substantive law. Additional examples of debiasing through substantive law are explored in Jolls (forthcoming) and Sunstein (forthcoming).

\subsection{Offsetting Effects}

We noted just above that sometimes neither debiasing through law nor strategies for insulating legal outcomes from the effects of bounded rationality may be an appropriate course of action. An important example here is the case in which a given form of boundedly rational behavior is offset by another aspect of bounded rationality that tends in the opposite direction. Simply put, some departures from unbounded rationality can counteract others; we gave several examples in section 2 above. In such cases efforts either to engage in debiasing through law in response to a given form of bounded rationality, or to insulate legal outcomes from the effects of this form of bounded rationality, might actually make things worse rather than better.

Whether a given aspect of bounded rationality is in fact likely to be in an offsetting relationship with some other feature of bounded rationality will 
of course depend on the particular context, as noted in section 2 above. $^{32}$ Obviously, if an offsetting relationship with another feature of bounded rationality exists, a legal response - whether debiasing through law or an “insulating” strategy - may well be unwarranted.

\subsection{Correcting Factual Errors}

Section 2 above distinguished between debiasing through law in response to judgment errors (section 2.1) and debiasing through law in response to departures from expected utility theory (section 2.2). In the latter context, the government intervention obviously cannot be said to operate simply by correcting clear factual errors; and thus in section 2.2 we assumed rather than argued that, in certain contexts, reducing willingness to accept to the level of willingness to pay was a suitable target of debiasing through law. But when debiasing through law is a response to a clear factual error, the normative impetus for the government intervention is far more straightforward.

Debiasing through law in response to a clear factual error - for instance, a consumer's underestimation of the probability that an accident will occur - is indistinguishable (in terms of the normative impetus for the intervention) from a vast array of existing government initiatives. In countless domains, the government either discloses information on its own or requires disclosure by those providing goods or services in response to erroneous factual perceptions people would otherwise hold (e.g., Stiglitz 1986, pp. 90-91). When people have erroneous views about factual matters, there is broad agreement that government may legitimately concern itself with correcting their errors. It seems hard to think of a plausible objection to this ground for government intervention (although of course, as noted already, intervention may ultimately prove unwarranted if its benefits are not justified by its costs).

Note the distinction between our focus here on debiasing through law and possible strategies of what might be called "biasing through law." In some cases, social planners may wish that people's factual estimates diverged from the truth; for example, planners may want people to overestimate the

${ }^{32}$ Jolls, Sunstein and Thaler (1998a, pp.1524-25), for instance, discuss the partially offsetting relationship between hindsight bias and optimism bias in the tort law context. 
probability of being caught if they choose to speed or evade taxes. But strategies directed toward such objectives, even if socially desirable, would not be forms of debiasing through law within our definition, as they would not be responding to any identified form of bounded rationality.

While the government's ends in our analysis are thus uncomplicated (either because the ends involve correction of clear factual errors or because, as in section 2.2, we have simply assumed that eliminating the endowment effect is a suitable target of government action ${ }^{33}$ ), the means employed in debiasing through law require further discussion. In the example of debiasing through consumer safety law, for instance, the government action in question involves harnessing separate departures from unbounded rationality to correct individuals' errors. Mechanisms of this type raise important and distinctive issues, to which we now turn.

\subsection{Heterogeneous Actors}

As recent literature has appropriately emphasized, not all individuals are likely to be boundedly rational, at least not to the same degree (e.g., Mitchell 2002, pp. 83-119, 139-67). As noted above, an important virtue of debiasing through law is that, in contrast to "insulating" strategies, the approach of debiasing through law can often avoid significant effects on individuals who do not exhibit bounded rationality. But in some circumstances, a strategy of debiasing through law could introduce new distortions through its effect on those who did not previously exhibit bounded rationality.

Consider, for instance, the strategic employment of the availability heuristic in response to optimism bias, discussed in section 2.1.1 above. In this case, the legal intervention conceivably could distort the behavior of individuals who did not suffer from optimism bias in the first place. For those who previously had an accurate understanding of the situation, such strategies for debiasing through law could produce a kind of unrealistic pessimism. In such cases, it is no longer possible to say that, even if the legal intervention does not provide much help, it is unlikely to cause much harm. (Note the contrast with traditional strategies of providing information to those who previously lacked it; such strategies should not significantly affect those who

${ }^{33}$ For normative discussion of government intervention in the context of (among other things) the endowment effect, see Sunstein and Thaler (2003). 
already possessed the information (e.g., Camerer et al. 2003, pp. 1230-37), though perhaps such strategies might prompt responsive behavior - for instance by affected firms through their pricing strategies - that would in turn affect those who did not initially suffer from information failures.)

A similar problem arises with respect to debiasing through corporate law in the form of the Sarbanes-Oxley Act. If, among the set of heterogeneous corporate boards, some do not exhibit optimistically biased judgments on the part of inside directors, then the legally-mandated presence of outsiders on the board could introduce distortions (for instance, because outside directors are less well-informed than inside directors) for boards whose behavior was previously undistorted. So too, the strategies described in section 2.2 for debiasing through law in response to the endowment effect conceivably could alter measures of value for those who did not initially exhibit an excess of willingness to accept over willingness to pay.

In some cases, actors who do not suffer from a particular form of bounded rationality, such as optimism bias, will also be free of other forms of bounded rationality, such as reliance on the availability heuristic. If those who are immune from optimism bias also tend to be immune from availability bias, then the strategies described above for debiasing through the availability heuristic should not affect those who did not previously suffer from optimism bias. In such cases, strategies for debiasing through law - like traditional informational strategies (Camerer et al. 2003, pp. 1230-37) should not affect those who did not exhibit bounded rationality prior to the legal intervention.

When the absence of one form of bounded rationality correlates in this way with the absence of others, strategies for debiasing through law fit well with the broader emerging theme, noted above, of adopting approaches that respond to bounded rationality but avoid imposing significant costs on those who do not exhibit this type of behavior. A leading illustration of such a strategy is "cooling periods" before important decisions are made (e.g., Camerer et al. 2003, pp. 1238-47).

In all of our examples of debiasing through substantive law in section 2 above, the government intervention is unlikely to be entirely cost-free for those who did not previously show bounded rationality. But even the simple provision of information by government - often a wholly uncontroversial strategy - will impose some costs on those who did not err prior to the intervention, simply because of the burden of processing the information. If 
the intervention produces important benefits for those who are prone to bounded rationality, then the intervention may be desirable even if it imposes modest costs on others. Here, as in other contexts, the only option is to weigh the effects of the different possible strategies. Of course efforts to debias people through law should be undertaken, whenever possible, in ways that do not produce confusion or misperception, as we discuss more fully in the next subsection.

\subsection{Overshooting}

The means employed by government in debiasing through law can create the risk of overshooting. If, for instance, truthful narratives are used in the context of consumer safety law, individuals who previously showed optimism bias might be led to exaggerate the risks of consumer products. The effort to debias through law would then be producing biases and errors of its own.

But this concern is not in any way specific to debiasing through law as distinguished from conventional "insulating" strategies; overshooting is

always a possible danger. Undoubtedly experimentation would be required to calibrate the degree to which availability or another form of bounded rationality would need to be brought to bear in engaging in debiasing through law; so too, experimentation is necessary under an "insulating" approach to determine the appropriate level or scope of the legal response. The problem of the scope of a legal corrective, and the risk of overshooting, are general, not specific to the means used in debiasing through law - although naturally if this problem is severe enough then a governmental response of any sort may be unwarranted.

\subsection{Autonomy}

A more fundamental concern with debiasing through law involves individual autonomy. When government is engaged in (what it considers to be) "debiasing," there is a risk that it will manipulate its citizens to serve its own objectives. If officials “debias," they might be violating the autonomy of ordinary people. In some cases of debiasing through law in response to judgment errors, for instance, government may be correcting bounded rationality by exploiting it, in a way that might give rise to fears of manipulation. In the applications discussed in section 2, this occurs perhaps 
most obviously with respect to harnessing availability and framing in response to consumers' optimism bias. The risk of manipulation in the guise of debiasing through law - a risk that may not be raised by "insulating" strategies - appears especially disturbing in light of the fact that regulators are often self-serving or vulnerable to the interests of powerful private groups.

It is clear that if bounded rationality is pervasive, then an informed government is likely to have little trouble in manipulating people in its preferred directions. Such a government might engage in manipulation on its own behalf, or in support of its preferred interests. Government should of course respect its citizen. As emphasized, for instance, by the publicity condition in John Rawls's A Theory of Justice (1971, p. 133), regulators should generally refrain from engaging in acts that could not be defended in public to those who are subject to those acts. If a public defense could not be made, the acts are an insult to the autonomy of citizens. (Deontologists will emphasize the insult to autonomy as such; consequentialists will of course care about violations of the publicity condition only insofar as such violations have bad consequences.)

Is debiasing through law a violation of the publicity condition? Much of the time, the answer is negative. If, for example, government harnesses availability and framing in response to consumers' optimism bias, there is no reason to think government would have to conceal or make ambiguous its efforts to correct people's errors. Citizens need not be disturbed to learn what government is doing, and there is no reason for regulators to keep their efforts secret. To be sure, it may be troubling for some people to learn that government has "framed" a message to produce the desired result, but there is no violation of the publicity condition. ${ }^{34}$

As we have noted, government efforts to correct individuals' factual mistakes are widespread and largely uncontroversial. The worry about government "manipulation," if there is a worry, arises even with the widely accepted approach under which the government corrects simple information failures (where people are mistaken because they lack information entirely, rather than because they process information in a biased way) among citizens. As framing effects as well as other departures from unbounded rationality reveal, there is usually no neutral way to present information. Whenever the government is presenting even accurate information, it is

${ }^{34}$ See Luban (1996) for further discussion of the publicity condition. 
making choices about presentation - choices that will inevitably affect how citizens perceive the reality around them. Thus, it is far too simple, and behaviorally naive, to draw a sharp line between acceptable "provision of information" and unacceptable "mind control." Unless the concern with government manipulation is strong enough to suggest that the government should never provide information to its citizens (an implausible suggestion), there must be at least some willingness to tolerate the prospect of government influence over citizens' perceptions of reality and the attendant risk of government manipulation.

Suppose, for example, that smokers were found to discount the risks that accompany smoking, in part because of optimism bias. If so, it is hardly obvious that government would violate their autonomy by giving a more accurate sense of those risks, even if the best way of giving that accurate sense were through concrete accounts of suffering. And it is also far from clear in such a case that the government could not publicly defend its strategy to citizens as required by the publicity condition; recall in this connection the American Legacy Foundation letters campaign described in section 2.1.1 above.

This is not to say, of course, that no form of debiasing through law could be objectionable on autonomy grounds. Some forms might resemble systems of propaganda in clear violation of the publicity condition. If so, there is not only an insult to autonomy; there is also a real risk that the onesidedness and aggressiveness of the government's effort will be exposed. If this happens, public trust will unquestionably be reduced. And if trust is reduced, government strategies are much less likely to succeed. For many people, these instrumental concerns will seem aggravated by strong moral ones. At least when minors are not involved, the law should treat citizens with respect, and extreme marketing strategies (going well beyond what we have suggested in discussing strategies for debiasing through law) violate that principle. In addition, debiasing through law in response to the endowment effect, as discussed in section 2.2 above, may prove ineffective if the debiasing effort is disclosed; if people know that the government has adopted a particular legal rule in order to reduce willingness to accept to the level of willingness to pay, then it is possible that willingness to accept will no longer drop under that rule.

With respect to autonomy, no general conclusion is likely to make sense. The nature and force of the objections discussed above will obviously depend on the setting and the particular strategy involved. However, these 
objections seem weakest when government is responding to a form of bounded rationality that unquestionably qualifies as an "error” and is using methods that do not distort the facts.

\section{7 "Behavioral Bureaucrats”}

Nothing said thus far denies the important fact that legal policymakers and administrators, including those who seek to engage in debiasing through law or other corrective strategies, will often suffer from bounded rationality themselves. (Indeed, existing literature extends the traditional focus on debiasing of boundedly rational juries or other adjudicative decision makers by considering debiasing of boundedly rational government bureaucrats (e.g., Rachlinski and Farina 2002, pp. 582-90, 596-600, 603-06; Seidenfeld 2002, pp. 508-26).) No less than ordinary people, bureaucrats use heuristics and are subject to predictable biases; they are also susceptible to the influence of powerful private groups with stakes in the outcome. Indeed, the very accountability of bureaucrats suggests that they will be affected by the bounded rationality of the citizenry. It is certainly plausible to worry that efforts at debiasing by behaviorally sophisticated regulators may operate in practice to reward well-organized private groups, or perhaps to promote the interests of regulators themselves.

In this light we do not make the naive and implausible suggestion that in the real world, strategies for debiasing through law will always be wellmotivated and well-designed. (Nor will strategies designed to insulate legal outcomes from the effects of bounded rationality.) Our claim is only that if people exhibit bounded rationality, debiasing through law may often be a promising response - one that it would be foolish to eliminate from the government's repertoire. $^{35}$

\section{Conclusion}

The central goal of this paper has been to draw attention to the distinctiveness and the potential value of debiasing through law, especially debiasing through substantive law. The social science literature has devoted a great deal of effort to the study of debiasing of boundedly rational actors, but

${ }^{35}$ For a general discussion of "behavioral bureaucrats," see Jolls, Sunstein and Thaler (1998a, pp. 1543-44). 
with little effort to see how law and legal institutions might accomplish that goal. Those interested in bounded rationality and law have argued mostly that legal outcomes should be insulated from the effects of boundedly rational behavior, and in some cases that debiasing of boundedly rational actors should be pursued through changes in procedural rules governing the adjudicative process. It is tempting to contend that if most people make welfare-reducing choices because of bounded rationality, their choices should be blocked. In our view, debiasing through law - especially debiasing through substantive law - is a distinctive and sometimes far preferable alternative to the strategy of insulating legal outcomes from the effects of bounded rationality. Such debiasing often promises to be both more successful and less invasive than more conventional alternatives.

Nothing in our analysis is inconsistent with the claim that in some contexts, unfettered markets are the best response to bounded rationality. Such markets might reduce the effects of bounded rationality by raising the stakes, as suggested in section 2.1.1 above; it is also possible that the costs of boundedly rational behavior are, in some contexts, lower than the costs of any effort to counteract it. In some contexts, private actors, alert to the risk of bounded rationality, will take corrective action on their own. We also do not disagree with the now-familiar suggestion that in the face of bounded rationality, aggressive regulation - some form of "insulating” strategy might sometimes be justified. ${ }^{36}$ Instead our aim has been to chart the possibility of a middle course, one that asks legal institutions not to ignore people, but instead to reduce their bounded rationality.

In some contexts, debiasing through law is likely to be effective, costjustified, and minimally intrusive. We believe that some areas of the law reveal an appreciation of these points and hence an implicit behavioral rationality, using legal strategies as a mechanism for debiasing of boundedly rational actors. Our principal goal has been to understand those strategies in these terms and to explore the possibility of building on them to do far more.

${ }^{36}$ Jolls, Sunstein and Thaler (1998a) provide various examples. 


\section{References}

Arlen, Jennifer, Matthew Spitzer, and Eric Talley. 2002. Endowment Effects Within Corporate Agency Relationships. Journal of Legal Studies 31:1-37.

Armour, David, and Shelley E. Taylor. 2002. When Predictions Fail: The Dilemma of Unrealistic Optimism. Pp. 334-47 in Heuristics and Biases: The Psychology of Intuitive Judgment, edited by Thomas Gilovich, Dale Griffin, and Daniel Kahneman. New York: Cambridge University Press.

Asch, Solomon. 1955. Opinions and Social Pressure. Scientific American 193:31-40.

Ayres, Ian, and Eric Talley. 1995. Solomonic Bargaining: Dividing a Legal Entitlement to Facilitate Coasean Trade. Yale Law Journal 104:1027-1117.

Babcock, Linda, George Loewenstein, Samuel Issacharoff, and Colin Camerer. 1995. Biased Judgments of Fairness in Bargaining. American Economic Review 85:1337-43.

Babcock, Linda, George Loewenstein, and Samuel Issacharoff. 1997. Creating Convergence: Debiasing Biased Litigants. Law and Social Inquiry 22:913-25.

Baron, Robert S., Joseph A. Vandello, and Bethany Brunsman. 1996. The Forgotten Variable in Conformity Research: Impact of Task Importance on Social Influence. Journal of Personality and Social Psychology 71:915-27.

Beales, Howard, Richard Craswell, and Steven C. Salop. 1981. The Efficient Regulation of Consumer Information. Journal of Law \& Economics 24:491539.

Benartzi, Shlomo, and Richard H. Thaler. 1999. Risk Aversion or Myopia? Choices in Repeated Gambles and Retirement Investments. Management Science 45:364-81.

Bhagat, Sanjai, and Bernard S. Black. 1999. The Uncertain Relationship between Board Composition and Firm Performance. Business Lawyer 54:921-63.

Brown, Roger. 1985. Social Psychology, the Second Edition. New York: Free Press.

Brudney, Victor. 1982. The Independent Director - Heavenly City or Potemkin Village? Harvard Law Review 95:597-659.

Calabresi, Guido, and A. Douglas Melamed. 1972. Property Rules, Liability Rules, and Inalienability: One View of the Cathedral. Harvard Law Review 85:1089-1128. 
Camerer, Colin, Samuel Issacharoff, George Loewenstein, Ted O’Donoghue, and Matthew Rabin. 2003. Regulation for Conservatives: Behavioral Economics and the Case for "Asymmetric Paternalism." University of Pennsylvania Law Review 151:1211-44.

Craig, Samuel, Brian Sternthal, and Clark Leavitt. 1976. Advertising Wearout: An Experimental Analysis. Journal of Market Research 13:365-72.

Craswell, Richard. 1985. Interpreting Deceptive Advertising. Boston University Law Review 65:657-732. . 1981. The Identification of Unfair Acts and Practices by the Federal Trade Commission. Wisconsin Law Review 1981:107-53.

Dewan, Shaila K. 2004. The New Public Service Ad: Just Say “Deal with It,” N.Y. Times, January 11.

Druckman, James N. 2001. Using Credible Advice to Overcome Framing Effects. Journal of Law Economics \& Organization 71:62-82.

Easterbrook, Frank H., and Daniel R. Fischel. 1982. Corporate Control Transactions. Yale Law Journal 91:698-737.

Farnsworth, Ward. 2003. The Legal Regulation of Self-Serving Bias. University of California Davis Law Review 37:567-603.

Fischhoff, Baruch. 1982. Debiasing. Pp. 422-44 in Judgment under Uncertainty: Heuristics and Biases, edited by Daniel Kahneman, Paul Slovic, and Amos Tversky. New York: Cambridge University Press.

Glaeser, Edward. 2004. Psychology and the Market. American Economic Review 94:408-13.

Gulati, G. Mitu, Jeffrey J. Rachlinski, and Donald C Langevoort. 2004. Fraud By Hindsight. Northwestern University Law Review 98:773-825.

Guthrie, Chris. 2000. Framing Frivolous Litigation: A Psychological Theory. University of Chicago Law Review 67:163-216.

Jolls, Christine. Forthcoming. Antidiscrimination Law's Effects on Unconscious Bias. (Behavioral Economics and Antidiscrimination Law). . 1998. Behavioral Economic Analysis of Redistributive Legal Rules. In Symposium: The Legal Implications of Psychology: Human Behavior, Behavioral Economics, and the Law. Vanderbilt Law Review 51:1653-77. Jolls, Christine, Cass R. Sunstein, and Richard Thaler. 1998a. A Behavioral Approach to Law and Economics. Stanford Law Review 50:1471-1550. . 1998b. Theories and Tropes: A Reply to Posner and Kelman, Stanford Law Review 50:1593-1608. 
Kahneman, Daniel, Jack Knetsch, and Richard Thaler. 1990. Experimental Tests of the Endowment Effect and the Coase Theorem. Journal of Political Economy 98:1325-48.

Kahneman, Daniel, and Amos Tversky. 1979. Prospect Theory: An Analysis of Decision Under Risk. Econometrica 47:263-92.

Kaplow, Louis, and Steven Shavell. 1996. Property Rules Versus Liability Rules: An Economic Analysis. Harvard Law Review 109:713-90.

Korobkin, Russell. 2003. The Endowment Effect and Legal Analysis. In Symposium: Empirical Legal Realism: A New Social Scientific Assessment of Law and Human Behavior. Northwestern University Law Review 97:122793.

Korobkin, Russell and Thomas Ulen. 2000. Law and Behavioral Science: Removing the Rationality Assumption from Law and Economics. California Law Review 88:1051-1144.

Kunreuther, Howard. 1982. The Economics of Protection Against Low Probability Events. Pp. 195-215 in Decision Making: An Interdisciplinary Inquiry, edited by Gerardo R. Ungson and Daniel Braunstein. Boston: Kent Publishing Co.

Kysar, Douglas A. 2003. The Expectations of Consumers. Columbia Law Review 103:1700-90.

Langevoort, Donald C. 2001. The Human Nature of Corporate Boards: Law, Norms, and the Unintended Consequences of Independence and Accountability. Georgetown Law Journal 89:797-832. . 1998. Behavioral Theories of Judgment and Decision Making in Legal Scholarship: A Literature Review. Vanderbilt Law Review 51:14991540 .

. 1997. Organized Illusions: A Behavioral Theory of Why Corporations Mislead Stock Market Investors (And Cause Other Social Harms). University of Pennsylvania Law Review 146:101-72.

Latin, Howard. 1994. “Good” Warnings, Bad Products, and Cognitive Limitations. UCLA Law Review 41:1193-1295.

Lewinsohn-Zamir, Daphna. 2001. The Choice Between Property Rules and Liability Rules Revisited: Critical Observations from Behavioral Studies. Texas Law Review 80:219-60.

Luban, David. 1996. The Publicity Principle. Pp. 154-98 in The Theory of Institutional Design edited by Robert E. Goodin. New York: Cambridge University Press. 
Magat, Wesley A. and W. Kip Viscusi. 1992. Informational Approaches to Regulation. Cambridge, Mass.: The MIT Press.

Meyerowitz, Beth E., and Shelly Chaiken. 1987. The Effect of Message Framing on Breast Self-Examination: Attitudes, Intentions, and Behavior. Journal of Personality and Social Psychology 52:500-10.

Mitchell, Gregory. 2002. Why Law and Economics’ Perfect Rationality Should Not Be Traded for Behavioral Law and Economics' Equal Incompetence. Georgetown Law Journal 91:67-167.

Nisbett, Richard E., Eugene Borgida, Rick Crandall, and Harvey Reed. 1982. Popular Induction: Information Is Not Necessarily Informative. Pp. 101-16 in Judgment Under Uncertainty: Heuristics and Biases, edited by Daniel Kahneman, Paul Slovic, and Amos Tversky. New York: Cambridge University Press.

Paredes, Troy. 2004. Too Much Pay, Too Much Deference: Is CEO Overconfidence the Product of Corporate Governance? Working Paper No. 04-08-02. Washington University in St. Louise School of Law, MO.

Parisi, Francesco, and Vernon Smith. 2004. The Law and Economics of Irrational Behavior. Stanford University Press.

Peters, Philip G., Jr. 1999. Hindsight Bias and Tort Liability: Avoiding Premature Conclusions. Arizona State Law Journal 31:1277-1314.

Petersen, Melody. 2003. Breastfeeding Ads Delayed By a Dispute Over Content. New York Times, December 4.

Plott, Charles R., and Kathryn Zeiler. 2005. The Willingness to Pay Willingness to Accept Gap, the "Endowment Effect," Subject Misconceptions, and Experimental Procedures for Eliciting Valuations. The American Economic Review 95:530-45.

Prentice, Robert A., and Mark E. Roszkowski. 1991-92. “Tort Reform” and the Liability "Revolution": Defending Strict Liability in Tort for Defective Products. Gonzaga Law Review 27:251-302.

Rachlinski, Jeffrey. 2003. The Uncertain Psychological Case for Paternalism. In Symposium: Empirical Legal Realism: A New Social Scientific Assessment of Law and Human Behavior. Northwestern University Law Review 97:1165-1225.

. 2000. The New “Law” and Psychology: A Reply to Critics, Skeptics, and Cautious Supporters. Cornell Law Review 85:739-66. . 1998. A Positive Psychological Theory of Judging in Hindsight. University of Chicago Law Review 65:571-625. 
Rachlinski, Jeffrey, and Cynthia R. Farina. 2002. Cognitive Psychology and Optimal Governmental Design. Cornell Law Review 87:549-615.

Rachlinski, Jeffrey, and Forest Jourden. 1998. Remedies and the Psychology of Ownership. In Symposium: The Legal Implications of Psychology: Human Behavior, Behavioral Economics, and the Law. Vanderbilt Law Review 51:1541-82.

Romano, Roberta. 2005. The Sarbanes-Oxley Act and the Making of Quack Corporate Governance. Yale Law Journal 114:1521-1611. . 1996. Corporate Law and Corporate Governance. Industrial and Corporate Change 5:277-340.

Rasmussen, Robert K. 1998. Behavioral Economics, the Economic Analysis of Bankruptcy Law, and the Pricing of Credit. Vanderbilt Law Review 51:1679-1703.

Rawls, John. 1971. A Theory of Justice. Cambridge, Mass.: Belknap Press of Harvard University Press.

Sale, Hillary. 2004. Delaware's Good Faith. In Symposium: Enron and the Future of U.S. Corporate Law. Cornell Law Review 89:456-95.

Schwartz, Alan. 1988. Proposals for Products Liability Reform: A Theoretical Synthesis. Yale Law Journal 97:353-419.

Schwartz, Alan, and Louis L. Wilde. 1983. Imperfect Information in Markets for Contract Terms: The Examples of Warranties and Security Interests. Virginia Law Review 69:1387-1485.

Seidenfeld, Mark. 2002. Cognitive Loafing, Social Conformity, and Judicial Review of Agency Rulemaking. Cornell Law Review 87:486-548.

Sloan, Frank A., Donald H. Taylor, and V. Kerry Smith. 2003. The Smoking Puzzle: Information, Risk Perception, and Choice. Cambridge, Mass.: Harvard University Press.

Slovic, Paul, Melissa Finucane, Ellen Peters, and Donald G. MacGregor. 2002. The Affect Heuristic. Pp. 397-420 in Heuristics and Biases: The Psychology of Intuitive Judgment, edited by Thomas Gilovich, Dale Griffin, and Daniel Kahneman. New York: Cambridge University Press.

Stallard, Merrie Jo, and Debra L. Worthington. 1998. Reducing the Hindsight Bias Utilizing Attorney Closing Arguments. Law and Human Behavior 22:671-83.

Stiglitz, Joseph E. 1986. Economics of the Public Sector. New York: W.W. Norton. 
Sunstein, Cass R. Forthcoming. Boundedly Rational Borrowing: A Consumers' Guide. University of Chicago Law Review. . 2003. Why Societies Need Dissent. Cambridge, Mass.: Harvard University Press. . 2002. Probability Neglect: Emotions, Worst Cases, and Law. Yale Law Journal 112:61-107. 2000. Behavioral Law and Economics. New York: Cambridge University Press.

Sunstein, Cass R., and Richard H. Thaler. 2003. Libertarian Paternalism Is Not An Oxymoron. University of Chicago Law Review 70:1159-1202.

Tor, Avishalom. 2002. The Fable of Entry: Bounded Rationality, Market Discipline and Legal Policy. Michigan Law Review 101:482-568.

Tversky, Amos and Daniel Kahneman. 1983. Extensional Versus Intuitive Reasoning: The Conjunction Fallacy in Probability Judgment. Psychological Review 90:293-315.

Viscusi, W. Kip. 1988. Predicting the Effects of Food Cancer Risk Warnings on Consumers. Food Drug Cosmetic Law Journal 43:283-314.

Viscusi, W. Kip and Wesley A. Magat. 1987. Learning About Risk:

Consumer and Worker Response to Hazard Information. Cambridge, Mass.: Harvard University Press.

Weinstein, Neil D., and William M. Klein. 2002. Resistance of Personal Risk Perceptions to Debiasing Interventions. Pp. 313-23 in Heuristics and Biases: The Psychology of Intuitive Judgment, edited by Thomas Gilovich, Dale Griffin, and Daniel Kahneman. New York: Cambridge University Press. 


\section{Appendix: Strategies for Debiasing Through Law}

This appendix briefly summarizes some leading empirical research on debiasing of boundedly rational actors and its implications for debiasing through both substantive law and procedural rules governing the adjudicative process.

\begin{tabular}{|c|c|c|c|c|}
\hline & $\begin{array}{l}\text { Evidence of } \\
\text { unsuccessful } \\
\text { debiasing? }\end{array}$ & $\begin{array}{l}\text { Evidence of } \\
\text { successful } \\
\text { debiasing? }\end{array}$ & $\begin{array}{l}\text { Illustration of } \\
\text { debiasing } \\
\text { through } \\
\text { procedural } \\
\text { rules } \\
\text { governing the } \\
\text { adjudicative } \\
\text { process? }\end{array}$ & $\begin{array}{l}\text { Illustration of } \\
\text { debiasing } \\
\text { through } \\
\text { substantive } \\
\text { law? }\end{array}$ \\
\hline \multicolumn{5}{|l|}{$\begin{array}{l}\text { JUDGMENT } \\
\text { ERRORS }\end{array}$} \\
\hline Optimism bias & $\begin{array}{l}\text { Most } \\
\text { approaches } \\
\text { that directly } \\
\text { target } \\
\text { optimism bias. } \\
\text { Source: } \\
\text { Weinstein and } \\
\text { Klein (2002). }\end{array}$ & $\begin{array}{l}\text { Giving people } \\
\text { a concrete } \\
\text { sense of the } \\
\text { relevant harms } \\
\text { Source: Sloan, } \\
\text { Taylor and } \\
\text { Smith (2003). }\end{array}$ & & $\begin{array}{l}\text { Consumer } \\
\text { safety law } \\
\text { governing } \\
\text { warnings and } \\
\text { other } \\
\text { manufacturer } \\
\text { statements } \\
\text { (section } \\
2.1 .1 \text { ); } \\
\text { corporate law } \\
\text { governing } \\
\text { board } \\
\text { composition } \\
\text { (section } \\
2.1 .2 \text { ). } \\
\end{array}$ \\
\hline Hindsight bias & $\begin{array}{l}\text { Many } \\
\text { approaches } \\
\text { Source: } \\
\text { Fischhoff } \\
\text { (1982). }\end{array}$ & $\begin{array}{l}\text { Telling people } \\
\text { not to be } \\
\text { "Monday } \\
\text { morning } \\
\text { quarterbacks." } \\
\text { Source: } \\
\text { Stallard and } \\
\text { Worthington } \\
\text { (1998). }\end{array}$ & $\begin{array}{l}\text { Requiring } \\
\text { judges to } \\
\text { instruct jurors } \\
\text { not to be } \\
\text { "Monday } \\
\text { morning } \\
\text { quarterbacks.” } \\
\text { Source: Peters } \\
\text { (1999). }\end{array}$ & \\
\hline
\end{tabular}




\begin{tabular}{|c|c|c|c|c|}
\hline & $\begin{array}{l}\text { Evidence of } \\
\text { unsuccessful } \\
\text { debiasing? }\end{array}$ & $\begin{array}{l}\text { Evidence of } \\
\text { successful } \\
\text { debiasing? }\end{array}$ & $\begin{array}{l}\text { Illustration of } \\
\text { debiasing } \\
\text { through } \\
\text { procedural } \\
\text { rules } \\
\text { governing the } \\
\text { adjudicative } \\
\text { process? }\end{array}$ & $\begin{array}{l}\text { Illustration } \\
\text { of debiasing } \\
\text { through } \\
\text { substantive } \\
\text { law? }\end{array}$ \\
\hline $\begin{array}{l}\text { Self-serving } \\
\text { bias in } \\
\text { negotiations }\end{array}$ & $\begin{array}{l}\text { Alerting } \\
\text { people to } \\
\text { existence of } \\
\text { the bias } \\
\text { Source: } \\
\text { Babcock, } \\
\text { Loewenstein } \\
\text { and } \\
\text { Issacharoff } \\
\text { (1997). }\end{array}$ & $\begin{array}{l}\text { Asking people } \\
\text { to make other } \\
\text { side's } \\
\text { argument. } \\
\text { Source: } \\
\text { Babcock, } \\
\text { Loewenstein } \\
\text { and } \\
\text { Issacharoff } \\
\text { (1997). }\end{array}$ & $\begin{array}{l}\text { Requiring } \\
\text { litigants to } \\
\text { make other } \\
\text { side’s } \\
\text { argument. } \\
\text { Source: } \\
\text { Babcock, } \\
\text { Loewenstein } \\
\text { and } \\
\text { Issacharoff } \\
\text { (1997). }\end{array}$ & \\
\hline
\end{tabular}

${ }^{37}$ Self-serving bias overlaps to some degree with optimism bias, discussed at length in the text. An important distinction between the two categories is that self-serving bias generally relates to negotiation contexts - such as the litigation and settlement context - and, because of that fact, a major aspect of people's biased judgments within the domain of self-serving bias concerns the fairness of alternative outcomes. See Babcock et al. (1995, pp. 1337-38); Jolls, Sunstein and Thaler (1998a, pp. 1501-04). Self-serving conceptions of fairness are not usually categorized as a form of optimism bias; by contrast, bias in estimated probabilities of discrete outcomes - such as the result at trial - could quite readily be characterized as either self-serving bias or optimism bias. 


\begin{tabular}{|c|c|c|c|c|}
\hline & $\begin{array}{l}\text { Evidence of } \\
\text { unsuccessful } \\
\text { debiasing? }\end{array}$ & $\begin{array}{l}\text { Evidence of } \\
\text { successful } \\
\text { debiasing? }\end{array}$ & $\begin{array}{l}\text { Illustration of } \\
\text { debiasing } \\
\text { through } \\
\text { procedural } \\
\text { rules } \\
\text { governing the } \\
\text { adjudicative } \\
\text { process? }\end{array}$ & $\begin{array}{l}\text { Illustration } \\
\text { of debiasing } \\
\text { through } \\
\text { substantive } \\
\text { law? }\end{array}$ \\
\hline \multicolumn{5}{|l|}{$\begin{array}{l}\text { DEPARTURES } \\
\text { FROM } \\
\text { EXPECTED } \\
\text { UTILITY } \\
\text { THEORY } \\
\end{array}$} \\
\hline $\begin{array}{l}\text { Endowment } \\
\text { effect }\end{array}$ & $\begin{array}{l}\text { Many } \\
\text { approaches. } \\
\text { Source: } \\
\text { Kahneman, } \\
\text { Knetsch and } \\
\text { Thaler (1990). }\end{array}$ & $\begin{array}{l}\text { Protecting } \\
\text { entitlements } \\
\text { by liability } \\
\text { rules rather } \\
\text { than property } \\
\text { rules; having } \\
\text { agents make } \\
\text { decisions. } \\
\text { Sources: } \\
\text { Rachlinski and } \\
\text { Jourden } \\
\text { (1998); Arlen, } \\
\text { Spitzer and } \\
\text { Talley (2002). }\end{array}$ & & $\begin{array}{l}\text { Property law } \\
\text { governing } \\
\text { protection of } \\
\text { intellectual } \\
\text { property } \\
\text { entitlements } \\
\text { (section } \\
2.2 .1 \text { ); } \\
\text { agency law } \\
\text { (section } \\
2.2 .2 \text { ). }\end{array}$ \\
\hline
\end{tabular}

